\title{
Research on the relations among Achievement Goal Setting, Self-efficacy and English Learning Achievement of Engineering Graduate Students: A Structural Equation Modeling Approach
}

\author{
Tian Dong, Ya-Ting Tao ${ }^{*}$, Si-lai Zhang \\ School of Foreign Languages, North China Electric Power University, Baoding, 07100, China
}

DOI: $10.36348 /$ sijll.2020.v03i07.002

| Received: 20.07.2020 | Accepted: 27.07.2020 | Published: 30.07.2020

*Corresponding author: Ya-Ting Tao

\section{Abstract}

Achievement goal setting and self-efficacy are two critical variables influencing learning achievements. Many scholars have studied the relationship between two variables by correlation analysis, regression analysis or path analysis. These methods, however, neglect the measurement error at all, which are inconsistent with the reality. Through a questionnaire survey among 266 first-year academic engineering graduate students, this study aims to clarify the relations among achievement goal setting, self-efficacy (SE) and English learning achievement (ELA) of engineering graduate students. Integrating the advantages of conventional statistical methods, Structural Equation Model (SEM) not only takes the measurement error into consideration, but also could study the structures of constructs and the relations among them at same time. The result shows that: 1)Achievement approach goal has a direct positive influence on English learning achievement, mastery approach goal and performance avoidance goal having direct negative influence, and mastery avoidance goal hasn't obvious influence on English learning achievement; 2) Mastery approach goal has the best impact on self-efficacy, while performance avoidance goal has the worst impact on self-efficacy; 3) Self-efficacy, a mediating variable between achievement goal setting and English learning achievement, could improve English learning achievement efficiently.

Keywords: Achievement goal setting; self-efficacy; English learning achievement; structural equation modeling.

Copyright @ 2020: This is an open-access article distributed under the terms of the Creative Commons Attribution license which permits unrestricted use, distribution, and reproduction in any medium for non-commercial use (NonCommercial, or CC-BY-NC) provided the original author and source are credited.

\section{INTRODUCTION}

Among all individual factors influencing second language acquisition, English learning motivation is always regarded as one of the most dynamic one, and also one of the most important affective one which influences English learning achievement. Over the past few decades, researchers have paid considerable attention to the relations between English learning motivation and English learning achievements with remarkable achievements. Many scholars have proved that English learning motivation could predicate or significantly correlate with learning achievement. As extremely special and important elements of motivation, self-efficacy and achievement goal setting, however, haven't received adequate scholarly attention until recent years. A review of the related literature shows that recent studies in linguistics mainly focus on the relationship between two variables, for example, correlation analysis of goal setting and English learning achievement [1] correlation and regression analysis of self-efficacy and English learning achievement [2], and path analysis of selfefficacy and goal setting [3]. These methods, however, neglect the measurement error at all, which are inconsistent with the reality. Thus, more researches should be conducted to prove their claims. The affective factors influencing acquisition are interactional, so it's unreasonable to separate them from each other. Furthermore, as crucial elements of affective motivations, self-efficacy and goal setting, to some extent, must change with one's cognition. Previous studies, however, only kept eyes on the undergraduates. For those Graduate students who are badly in need of reading and writing papers, the relations among their achievement goal setting, self-efficacy and English learning achievement are subjects with high value. Compared with the above conventional statistical methods, SEM has the following edges: 1) handling multiple variables simultaneously; 2) taking measurement error into account; 3) studying the structures of constructs and the relations among them at the same time; 4) estimating the goodness of fit of the whole model. Selecting 266 first-year academic 
engineering graduate students from a National Key Universities in Hebei province as the subjects, this study, therefore, takes the initiative to examine the complex relations among achievement goal setting, self-efficacy and English learning achievement by structural equation model (SEM) and thus guiding graduate students to set accurate English learning goals and enhancing their self-efficacy and ability.

\section{LITERATURE REVIEW Achievement goal setting}

Achievement goal setting refers to a plan about the cognitive process which is a combination of cognition, emotion and behavioral outcome [4]. Ames [5] defined it as the reactions that students have to task, achievement and success. Pintrich [6] conceptualized it as an individual's general schema or theory for approaching the task, doing the task and evaluating their performance on the task. It is also a construct reflecting one's task choices, self-set goals, ability and effort mechanisms in learning and performance. The classifications of achievement goal setting have gone through three different stages, namely, dichotomous framework [5], trichotomous framework [4] and fourfactor framework [6]. Now, the four-factor framework has been widely accepted in that it's reasonable both in terms of theory and statistical significance [4]. Fourfactor framework including mastery approach goal, mastery avoidance goal, performance approach goal and performance avoidance goal, therefore, will be adopted in this study. Learners with mastery approach goal focus on mastering concepts and developing skills, while those with mastery avoidance goal are in attempt to avoid losing the existing skill and knowledge or failing to accomplish the task. For individuals with performance approach goal, they are eager to demonstrate their capabilities and receive positive feedback, while those with performance avoidance goal are concerned with hiding their lack of knowledge or ability and afraid of failure [4]. Mainly based on the framework of dichotomy and trichotomy, previous studies about achievement goal setting fail to take the influence of mastery avoidance goal into account. It is generally acknowledged that learners with mastery approach goal could get higher achievements and mastery approach goal also could affect scores by adjusting learning strategies in an indirect way. Learners with mastery avoidance goal and performance avoidance goal will get lower achievements. For the relations between performance approach goal and learning achievement, researchers have different views where some thought they positively correlate with each other while others argued they negatively correlate.

\section{Self-efficacy}

Self-efficacy is conceptualized as people's judgment or predication of their capabilities to execute and accomplish a specific type of performance [7]. It is, actually, derived from Bandura's reciprocal determination theory [7], which places great emphasis on the interactions among person, environment and behavior. Bandura maintained the sources of selfefficacy include mastery experience, vicarious experience, social persuasion and physiological and emotional states. Mastery experience is one's personal experience about ability in real action, which is the most influential one among four sources. Vicarious experience means individuals could evaluate themselves by observing those whose ability is similar to theirs. If the counterparts at the similar level could achieve success by sustained efforts, it could boost the observers' self-confidence to achieve the same task. Social persuasion means others' encouragements or discouragements have great impact on one's selfefficacy where it could boost self-efficacy under positive persuasions, or vice versa. Physiological and emotional states also affect one's self-efficacy. In other words, anxiety, stress, tension could dramatically reduce one's self-efficacy. Bandura [7] also pointed out self-efficacy plays a decisive role in choice-making, input of effort, attitudes towards difficulty, acquisition of new skill and emotional reactions in the later activities. According to reciprocal determination theory [7], Bandura held the view that self-efficacy is closely related with a specific activity and should be measured differently according to different contexts and tasks. In terms of English learning self-efficacy, some measured it from 2 dimensions, namely, English learning behavior and English learning ability while others measured it from 4 dimensions, namely, perceived basic capability, perceived control, perceived efforts and perceived environment. These dimensions, however, fail to predict the characteristics of English learning style of modern students. Considering the way of English learning under the influence of network environment (Apps, group chat,online teaching...), Liang Hong and Chen Ming [8] measured English learning self-efficacy from three dimensions, namely, English learning plan, English learning behavior and English learning strategy. This study, therefore, will be conducted based on 3 dimensions scale by Liang Hong and Chen Ming [8]. As an essential element influencing language acquisition, self-efficacy generates great impact on English learning achievement. Referring to the above dimensions, many scholars have studied the relations between self-efficacy and English learning achievement, but there is no consensus on it. Some researchers held the view that there is significant positive correlation between them [6], while others disputed that no significant correlation between them and at last, she found self-efficacy could affect English learning achievement in an indirect way by path analysis. Surprisingly, Wang Tianfa et al. [9] even proposed the relation of these two variables is dialectical, hence, mutually prediction.

\section{Relations among three variables}

Researches on the relation between selfefficacy and goal setting are quite scarce in the SLA. Taking the dichotomy framework as a reference [1], 
reported that compared with performance goal, mastery goal is more favorable to the improvement of selfefficacy. In terms of listening study, Munoz \& Jojoa [10] affirmed that self-efficacy significantly correlates with goal setting. Besides, based on trichotomy, some studies [5] supported that self-efficacy is a mediating variable between goal setting and other variables like English autonomous learning ability, English leaning strategies by path analysis. By studying senior high school students and non-English majors respectively, Dai Yan [2] also verified self-efficacy has a mediating effect between goal setting and English learning achievement.

Notwithstanding, a review of the related studies shows that little attention was paid to the interrelations among self-efficacy, goal setting and English learning achievement. Furthermore, methods like correlation, regression and path analysis were always given priority in these studies, which, however, neglect the measurement error at all, and it is inconsistent with the reality. In the same vein, previous studies, however, only kept eyes on the undergraduates. For those graduate students who are badly in need of reading and writing papers, the relations among their achievement goal setting, self-efficacy and English learning achievement are topics of great significance. A combination of achievement goal sets, self-efficacy and English learning achievement is conducive to illuminating the mediating effect of self-efficacy among English learning achievement and different dimensions of goal setting. For these reasons, selecting 266 firstyear academic engineering graduate students from a National Key Universities in Hebei province as the subjects, this study aims to examine the status quo of achievement goal setting, self-efficacy and English learning achievement of graduate students and complex relations among them by SEM.

\section{RESEARCH METHODS \\ The hypothesized model}

Based on the previous literature relating to this study, it is safely to draw the conclusion that achievement goal setting and self-efficacy have enormous effect on the English learning achievement. Given that, the initial model is developed by integrating 5 latent variables (mastery approach goal, mastery avoidance goal, performance approach goal and performance avoidance goal and self-efficacy) and 1 observed variable (English learning achievement). The hypothesized relations among them are depicted in Fig 1.

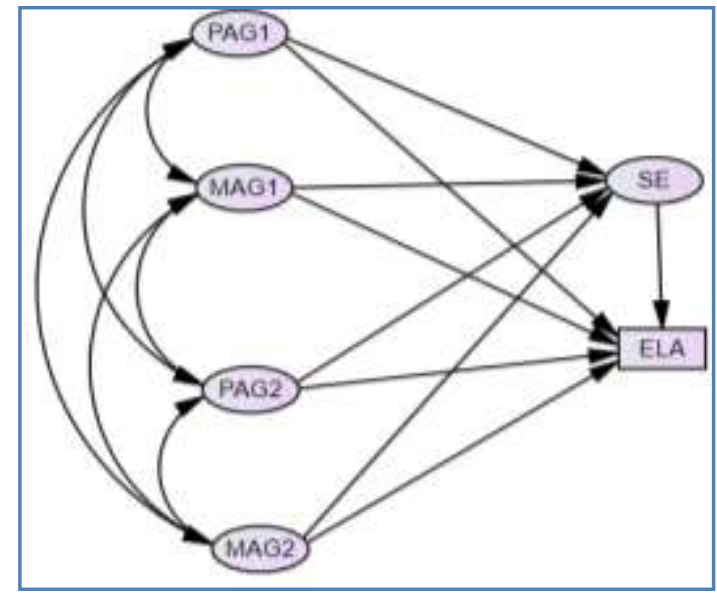

Fig-1: Hypothesized Model

(Note: PAG1: Performance approach goal ;

PAG2: Performance avoidance goal ; MAG1: Mastery approach goal; MAG2: Mastery avoidance goal; SE: Self-efficacy; ELA: English learning achievement)

The present study proposes the following hypotheses based on the related literature

- Performance approach goal positively correlates with self-efficacy and English learning achievement;

- Performance avoidance goal negatively correlates with self-efficacy and English learning achievement;

- Mastery approach goal positively correlates with self-efficacy and English learning achievement;

- Mastery avoidance goal negatively correlates with self-efficacy and English learning achievement;

- $\quad$ Self-efficacy positively correlates with English learning achievement.

\section{Participants}

When it comes to large sample analysis, SEM is often given priority, especially the number of samples over 200. This study, therefore, selected 266 first-year academic engineering graduate students from a National Key Universities in Hebei province, which are from 10 majors including Electric Engineering, Electric science and Technology, Environmental Science and 
Engineering and Mechanical engineering, etc. The effective returns-ratio is $97 \%$ with 258 valid questionnaires of 266. Their ages random from 21 to 28 $(M=23) .197$ students are male $(69.4 \%)$, and 79 are female $(30.6 \%)$. Their average score for the National Entrance Examination of English for Postgraduates is 62.97. Here, we use the following table (table 1) to present it more intuitively.

Table-1: Descriptive statistics of Participants

\begin{tabular}{|c|c|c|c|}
\hline & & Numbers & Percentage \\
\hline \multirow{5}{*}{} & Electric Engineering & 62 & $24.0 \%$ \\
\cline { 2 - 4 } & Electronic Science and Technology & 7 & $2.7 \%$ \\
\cline { 2 - 4 } & Power Engineering and Engineering Therm physics & 44 & $17.1 \%$ \\
\cline { 2 - 4 } & Heating, Gas Supply, Ventilating and Air Conditioning Engineering & 10 & $3.9 \%$ \\
\cline { 2 - 4 } Majors & Chemical Engineering and Technology & 9 & $3.5 \%$ \\
\cline { 2 - 4 } & Environmental Science and Engineering & 22 & $8.5 \%$ \\
\cline { 2 - 4 } & Mechanical Engineering & 30 & $11.6 \%$ \\
\cline { 2 - 4 } & Control Science and Engineering & 22 & $8.5 \%$ \\
\cline { 2 - 4 } & Information and Communication Technology & 30 & $11.6 \%$ \\
\cline { 2 - 4 } & Automation & 22 & $8.5 \%$ \\
\cline { 2 - 4 } & Total & 258 & $100.0 \%$ \\
\hline \multirow{3}{*}{ Gender } & Male & 179 & $69.4 \%$ \\
\cline { 2 - 4 } & Female & 79 & $30.6 \%$ \\
\cline { 2 - 4 } & Total & 258 & $100.0 \%$ \\
\hline
\end{tabular}

\section{Instruments}

The required data were collected through a questionnaire which is composed of three parts. The first part is about the basic information of the participants like age, gender and majors. The second and third parts are used to survey self-efficacy and achievement goal setting of students by scales developed by experts respectively. A pilot study was launched before a large-scale test in order to determine the final questionnaire. And the final questionnaire was filled out in some classes about 10 minutes in October 2019 and then collected immediately. Students were all informed of the objective of the study and the time needed to fill in it prior to distributing the questionnaires.

\section{National Entrance Examination of English for Postgraduates}

The score of National Entrance Examination of English for Postgraduates is adapted as English learning achievement in this study because it is systematically organized by China National Educational Examinations Authority (NEEA) with high scoring reliability.

\section{Self-efficacy questionnaire}

Self-efficacy questionnaire is an adaption of the self-efficacy scale by Liang Hong and Chen Ming
[8], which takes the features of postgraduates' English learning into consideration, for example, autonomous English learning and English learning plan setting by internet and measures 3 dimensions of self-efficacy: learning plan, learning strategies and learning behaviors through 17 items of 5-likerts from 1 (completely inconsistent) to 5 (completely consistent). According to SPSS 25.0, the result of a pilot study shows that the reliability is 0.810 , meeting the standards. We tested the reliability and validity of the questionnaire again after a large-scale study. According to the result (table 2) of construct validity, the values of KMO are 0.890. And the Bartlett Test of Sphericity shows a significance $(p=0.00)$, which means factor analysis could be made. Then, principle component analysis was made to find 3 main factors (eigenvalue>1) based on 16 items (q10 was deleted for not meeting statistical requirements). Referring to the original scale, we named the 3 factors as 'learning plan efficacy', 'learning strategy efficacy', and 'learning behavior efficacy' respectively. The factor loads of all items are above 0.4 (standard value), and the cumulative variances of the 3 factors covered $59.492 \%$ of the total items (table 3 ). Thus, the construct validity of this questionnaire is relatively high. The reliability of the questionnaire is 0.899 , and the Cronbach's $\alpha$ of the 3 factors are $0.803,0.878$ and 0.767 respectively, which proves the reliability of the questionnaire is comparatively high (table 4).

Table-2: KMO and Barlett's Test

\begin{tabular}{|l|l|l|}
\hline KMO & & $\mathbf{0 . 8 9 0}$ \\
\hline Bartlett's Test of Sphericity & Approx. Chi-Square & 1889.894 \\
\hline & df & 120.000 \\
\hline & Sig. & 0.000 \\
\hline
\end{tabular}


3: Total Variance Explained

\begin{tabular}{|c|c|c|c|}
\hline Factors & Eigenvalue & Variance & Commulative Variance \\
\hline learning plan efficacy & 3.851 & 24.069 & 24.069 \\
\hline learning strategy efficacy & 3.171 & 19.818 & 43.887 \\
\hline learning behavior efficacy & 2.497 & 15.605 & 59.492 \\
\hline
\end{tabular}

Table-4: Reliability Statistics

\begin{tabular}{|c|c|c|}
\hline & Cronbach's Alpha & N of Items \\
\hline Self-efficacy & 0.899 & 16 \\
\hline learning plan efficacy & 0.803 & 5 \\
\hline learning strategy efficacy & 0.767 & 5 \\
\hline learning behavior efficacy & 0.878 & 6 \\
\hline
\end{tabular}

\section{Achievement goal setting questionnaire}

Achievement goal setting questionnaire is an adaption of achievement goal setting scale by Liu Huijun et al. [11], which measures 4 dimensions of goal setting: mastery approach goal, mastery avoidance goal, performance approach goal and performance avoidance goal through 29 items of 5-likerts from 1(completely inconsistent) to 5(completely consistent). According to SPSS 25.0, the result of a pilot study shows that the reliability is 0.851 , meeting the standards. We tested the reliability and validity of the questionnaire again after a large-scale study. According to the result (table 5) of construct validity, the values of KMO are 0.886. And the Bartlett Test of Sphericity shows a significance $(p=0.00)$, which means factor analysis could be made.
Then, principle component analysis was made to find 4 main factors (eigenvalue> 1 ) based on 22 items ( 7 items were deleted for not meeting statistical requirements). Referring to the original scale, we named the 4 factors as 'mastery approach goal', 'mastery avoidance goal', 'performance approach goal' and 'performance avoidance goal' respectively. The factor loads of all items are above 0.4 (standard value), and the cumulative variances of the 4 factors covered $58.671 \%$ of the total items (table 6). Thus, the construct validity of this questionnaire is relatively high. The reliability of the questionnaire is 0.899 , and the Cronbach's $\alpha$ of the 4 factors are $0.841,0.878,0.815$ and 0.721 respectively, which proves the reliability of the questionnaire is comparatively high (table 7).

Table-5: KMO and Barlett's Test

\begin{tabular}{|l|l|l|}
\hline KMO & $\mathbf{0 . 8 8 6}$ \\
\hline Bartlett's Test of Sphericity & Approx. Chi-Square & 2512.465 \\
\hline & df & 231 \\
\hline & Sig. & 0.000 \\
\hline
\end{tabular}

Table-6: Total Variance Explained

\begin{tabular}{|c|c|c|c|}
\hline Factors & Eigenvalue & Variance & Commulative Variance \\
\hline Performance avoidance goal & 3.979 & 18.085 & 18.085 \\
\hline Performance approach goal & 3.569 & 16.221 & 34.307 \\
\hline Mastery approach goal & 3.291 & 14.958 & 49.265 \\
\hline Mastery avoidance goal & 2.069 & 9.407 & 58.671 \\
\hline
\end{tabular}

Table-7: Reliability Statistics

\begin{tabular}{|c|c|c|}
\hline & Cronbach's Alpha & N of Items \\
\hline Achievement goal setting & 0.899 & 22 \\
\hline Performance avoidance goal & 0.878 & 6 \\
\hline Performance approach goal & 0.841 & 7 \\
\hline Mastery approach goal & 0.815 & 6 \\
\hline Mastery avoidance goal & 0.721 & 3 \\
\hline
\end{tabular}

\section{Data analysis and processing}

Necessary data processing was executed at first by SPSS 25.0. Then, a structural model was analyzed by Amos 25.0. Every measurement model was tested prior to building a structural model, which is valid only when each measurement model is valid. After that, we put measurement models one by one into the structural model, importing the data file. The base model was then tested repeatedly referring to the revised suggestion and criteria by Amos 25.0 and respectively. Finally, we got the modified model and the following goodness-of-fit index for the model as follows: 
Table-8: Goodness-of-fit of the modified model

\begin{tabular}{|c|c|c|c|c|c|c|c|}
\hline Names & CMIN/DF & GFI & AGFI & CFI & IFI & RMSEA & RMR \\
\hline Standards & $\leq 5$ & $\geq 0.90$ & $\geq 0.90$ & $\geq 0.90$ & $\geq 0.90$ & $\leq 0.10$ & $\leq 0.08$ \\
\hline Result & 1.938 & 0.919 & 0.880 & 0.943 & 0.944 & 0.06 & 0.138 \\
\hline
\end{tabular}

Modified model and its standardized path coefficients are stated by the fig. 2 .

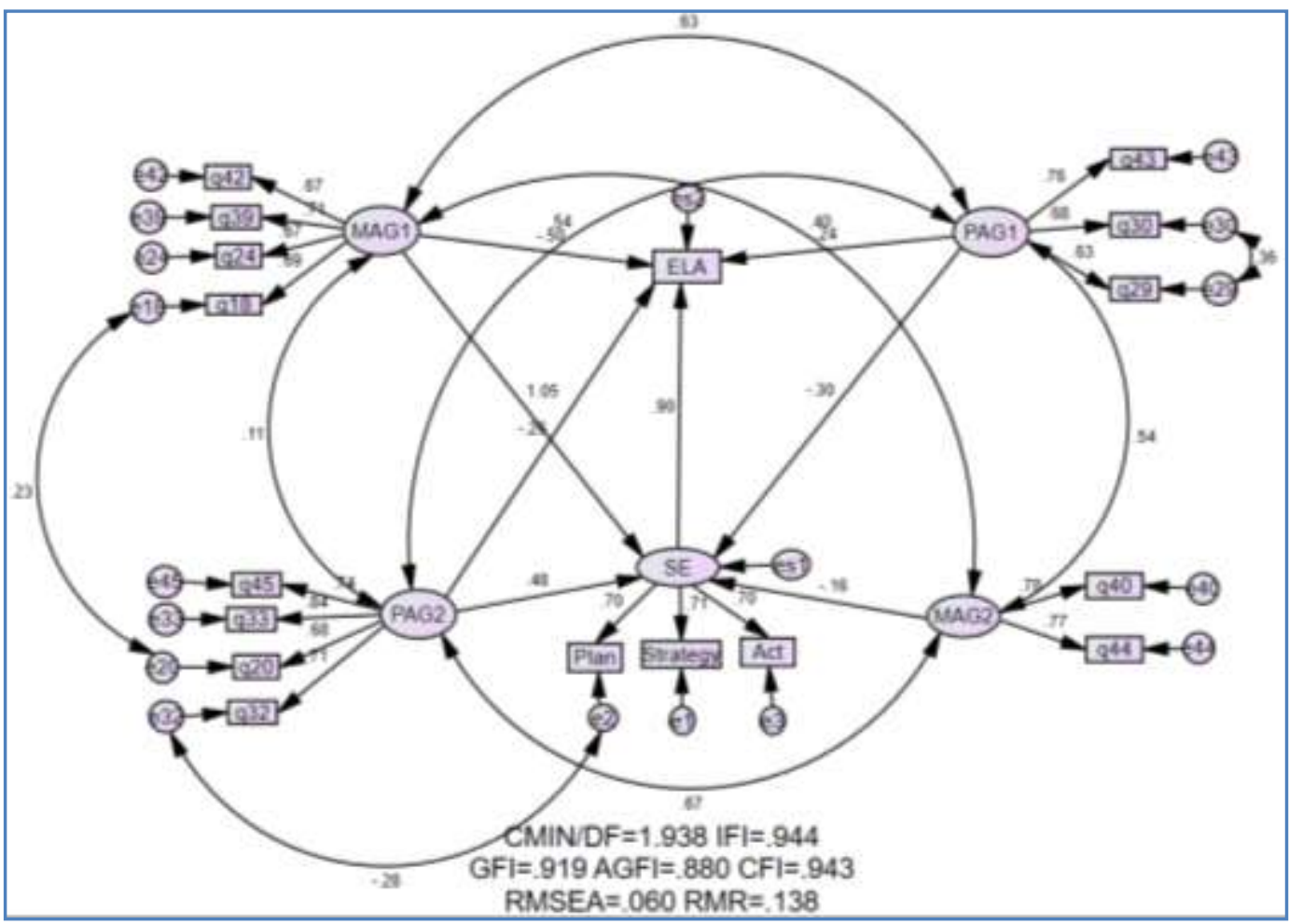

Fig-2: Structural model of SE, goal setting and ELA of engineering postgraduates

Table-9: Effects of the structural model

\begin{tabular}{|c|c|c|c|}
\hline Path & Direct effect & Indirect effect & Total effect \\
\hline PAG1-ELA & 0.24 & -0.27 & -0.03 \\
\hline PAG1-SE & -0.30 & 0.00 & -0.30 \\
\hline PAG2-ELA & -0.26 & 0.43 & 0.17 \\
\hline PAG2-SE & 0.48 & 0.00 & 0.48 \\
\hline MAG1-ELA & -0.50 & 0.95 & 0.45 \\
\hline MAG1-SE & 1.05 & 0.00 & 1.05 \\
\hline MAG2-ELA & 0.00 & -0.14 & -0.14 \\
\hline MAG2-SE & -0.16 & 0.00 & -0.16 \\
\hline SE-ELA & 0.90 & 0.00 & 0.90 \\
\hline
\end{tabular}

\section{RESULTS AND DISCUSSION}

As table 2 and figure 2 shows, the hypothesized model is acceptable. Four kinds of goals correlate with each other, which mean individuals could hold more than 1 goal at the same time. Nonetheless, there is no significant correlation between mastery avoidance goal and ELA (English learning achievement) which is below 0.1 . The relation between mastery approach goal and ELA is negative as well as the relation between performance approach goal and SE. And performance avoidance goal positively affect SE.

\section{The impact of goal setting on ELA}

The significant path $(0.24)$ from performance approach goal to ELA is consistent with the finding of Pintrich [6]. And the significant path (-0.26) from performance avoidance goal to ELA is in line with the result of Wolter [12]. Be that as it may, the relation (0.50 ) between mastery approach goal and ELA is negative, which is in contrast with the report by Zhang Weijian \& Yuan Lixin [1]. With a careful examination and analysis of this study, 2 reasons as follows can be stated to account for it. On one hand, the participants in the present study are graduate students, while those in previous study are other groups from senior high school or university. As it's known to us all, the graduate 
students are under great pressure from the papers because they must learn more disciplinary norms with the purpose to improve their pragmatic competence and writing ability by reading a lot of literature. The course of English Academic Writing is offered to them in university. Therefore, the graduate students with mastery approach goal tend to spend much time on reading literature for a good command of English in real situation by autonomous learning, not just on scores. On the other hand, a certain period of time should be given to get stable self-efficacy. As presented in table 3, the students with mastery approach goal could generate higher self-efficacy, which will improve the ELA at last. The secret of successful English learning lies in accumulation. Similarly, it takes certain time to read and write papers for the graduate students with the aim of publishing papers, and then they will be more proficient in all aspects of English learning including English learning achievement.

There is no significant relation between mastery avoidance goal and ELA on the ground that students with mastery avoidance goal tend to depend on the past experience and knowledge. They are unwilling to study new things and face the difficulties in English learning process for lack of great English learning passion. Although the students with mastery avoidance goal have the habit of consolidation of the existing knowledge, which will help them perform well in a short period, from the long run, they have the worst performance compared with those with the other goals, which is proved by the total effect $(-0.16)$ in table 3 .

From total effect (table 3), we could find mastery approach goal has the greatest positive effect (0.45) on ELA, closely followed by the performance avoidance goal on ELA (0.17), while mastery avoidance has the greatest negative effect on ELA. These findings are similar to those by other researchers [13].

\section{The impact of goal setting on SE}

As stated in Fig.2, the significant path from mastery approach goal to SE is 1.05 , over the maximum value (1). According to Joreskog, however, it is permitted to reach over 1 when two latent variables highly correlate with each other. The significant path from mastery avoidance goal to SE is -0.15 . Students with mastery approach goal usually pay attention to improve the ability and language skill with the belief that 'no pains, no gains', and tend to attribute the failure to the controllable factors like persistence and diligence, hence, high self-efficacy [4]. Performance approach goal has a significant negative effect $(-0.30)$ on SE, while performance avoidance goal has a significantly positive effect(0.48) on SE. It is, actually, reasonable in that students with performance approach goal are eager to receive the positive feedback from the outside. That's to say, they are easily affected by the fluctuations of ELA and opinions from others with great pressure and high level of anxiety. In contrast, those with performance avoidance goal are not affected by such pressure and anxiety because high achievement is not their taste at all. As a result, their self-efficacy is higher than those with performance approach goal.

From the above, we could find both mastery approach goal and avoidance approach goal have positive effect on SE, but the former (1.05) is much higher than the later $(0.48)$, which is in line with the claim of [1] that mastery goal is more favorable to SE than performance goal. Furthermore, SE plays a partial mediating role between mastery approach goal, performance approach goal and performance avoidance goal and ELA respectively. Also, SE plays a fully mediating role between mastery avoidance goal and ELA.

\section{The impact of SE on ELA}

Similarly, the significant positive path $(0.90)$ from SE to ELA is presented in Fig.2. High selfefficacy usually generates positive effect on choicemaking, input of effort, attitudes towards difficulty, acquisition of new skill and emotional reactions in the later activities so as to a good performance [31].

\section{CONCLUSION}

Through questionnaires and SEM, this study discussed the relations among achievement goal setting, self-efficacy and English learning achievement of engineering graduate students. The hypothesized model is highly consistent with the data we received, which means the model is stable and reliable. The findings of the study can be summarized as follows: 1)Achievement approach goal has a direct positive influence on English learning achievement, mastery approach goal and performance avoidance goal having direct negative influence, and mastery avoidance goal hasn't obvious influence on English learning achievement; 2) Mastery approach goal has the best impact on self-efficacy, while performance avoidance goal has the worst impact on self-efficacy; 3) Selfefficacy, a mediating variable between achievement goal setting and English learning achievement, could improve English learning achievement efficiently.

Under the hint of this study, we hope teachers could lead graduate students to set appropriate goals and stick to them during the courses of academic English teaching. Specifically, teachers should: 1) enable students to be clear about their own English achievement goals according to long-term goals; 2) guide students to the positive attribution in order to improve their self-confidence; 3) encourage them to handle the difficulties during English learning process. These methods will be conducive to set positive English achievement goal, improve self-efficacy and English learning achievement ultimately. 
Some limitations still exist, though we are quite prudent and careful during the study process. First, engineering postgraduates from only one university were selected in this study as a result of limited energy and costs. So the findings by the present study may be different for different universities of different regions. Besides, all the invalid samples were processed or deleted at first, but it is difficult to ensure all the items were answered by participants with great caution. Last but not least, the model in this study is not the unique optimal one, though the best goodness-fit index has been taken.

\section{REFERENCES}

1. Zhang, W., \& Yuan, L. (2004). The Effects of achievement goals on Non-English Majors' English Learning. Technology enhanced foreign language education, 9, 21-25.

2. Dai, Y. (2010). The Correlational Study of College EFL Students' Goal Orientations (Master's thesis). Available from China master's these full-text database.

3. Orientation, A. G., \& Ability, A. E. L. (2014). The Mediating Role of Self-efficacy [J]. Foreign Languages in China, 3.

4. Elliot, A. J., \& Mcgregor, H. A., Gable, S. (1999). Achievement goals, study strategies, and exam performance: A mediational analysis. Journal of Educational Psychology, 91, 549-563.

5. Ames, C. (1992). Classrooms: Goals, Structures, and Student Motivation. Journal of Educational Psychology, 84, 261-271.

6. Pintrich, P. R., \& De Groot, E. V. (1990). Motivational and self-regulated learning components of classroom academic performance. Journal of educational psychology, 82(1), 33.

7. Bandura, A. (1986). Social foundations of thought and action : a social cognitive theory. Journal of applied psychology, 12, 169.

8. Liang, H., \& Chen, M. (2018). Questionnaire Compilation for College Students' English Learning Self-efficacy. Journal of Ningbo University(Educational Science Edition),40, 22-27.

9. Wang, T. F., Yang, J. Y., Wang, Y., \& Zhang, H. (2007). College Students' English-Learning SelfEfficacy: Components and Causes [J]. Shandong Foreign Language Teaching Journal, 3.

10. Muñoz, L. B., \& Jojoa, S. T. (2014). How setting goals enhances learners' self-efficacy beliefs in listening comprehension. HOW Journal,21(1), 42-61.

11. Liu, H., \& Guo, D. (2003). Research on the relationship between test anxiety, achievement goal, and test performance. Developmental Psychology and Education, 2, 64-67.

12. Wolters, C. A. (2003). Understanding procrastination from a self-regulated learning perspective. Journal of educational psychology, 95(1), 179.

13. Patrick, H., Hicks, L., \& Ryan, A. M. (1997). Relations of perceived social efficacy and social goal pursuit to self-efficacy for academic work. The Journal of Early Adolescence, 17(2), 109-128.

14. Qin, X., \& Wen, Q. (2002). Motivational Structures of Non-English Majors.Foreign Language Teaching and Research, 46, 51-58. 